\title{
Coupled forest growth-hydrology modelling as an instrument for the assessment of effects of forest management on hydrology in forested catchments
}

\author{
J. Sutmöller, S. Hentschel, J. Hansen, and H. Meesenburg \\ Northwest German Forest Research Station, Göttingen, Germany \\ Received: 14 January 2010 - Revised: 16 June 2010 - Accepted: 29 June 2010 - Published: 9 March 2011
}

\begin{abstract}
The type and intensity of forest management directly influences regional catchment hydrology. Future forest management must optimise the effects of its practices to achieve sustainable management. With scenario analysis of forestry practices, the effects of different forest utilisation strategies on the hydrology of forested catchments can be temporally and spatially quantified.

The approach adopted in this study necessitated the development of an interactive system for the spatially distributed modelling of hydrology in relation to forest stand development. Consequently, a forest growth model was used to simulate stand development assuming various forest management activities. Selected simulated forest growth parameters were entered into the hydrological model to simulate water fluxes under different conditions of forest structure. The approach enables the spatially differentiated quantification of changes in the water regime (e.g. increased evapotranspiration).

The results of hydrological simulations in the study area, the Oker catchment (northern Harz Mountains), show that forests contribute to the protection of water systems because they have a balancing effect on the hydrological regime. As scenario simulations also suggest, however, forestry practices can also lead to substantial changes in water budgets of forested catchments. The preservation of the hydrological services of forests requires a sustainable and long-term forest conversion on the basis of current management directives for near natural silviculture. Management strategies on basis of moderate harvesting regimes are preferred because of their limited impact on the water budget.
\end{abstract}

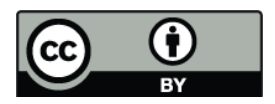

Correspondence to: J. Sutmöller (johannes.sutmoeller@nw-fva.de)

\section{Introduction}

Changes in forest structure and forest function can affect forest hydrology. Thus, through certain forest management activities (e.g. change in tree species), the compensatory effect of forests on the dynamics of water flow can be altered. This can, for example, lead to an intensification of flood events or a reduction in ground water recharge.

With the European Water Framework Directive (WFD), which came into effect in 2000 (European Parliament, 2000), for the first time, a scope for land management on the basis of river catchments was achieved. The aim of the WFD is to promote a good ecological status of surface and ground water. For the hydrology of forested catchments, this means primarily that deterioration in the water flow dynamics and groundwater recharge as a result of forest management and forest conversion must be avoided.

An interactive model system was developed to facilitate the assessment of the effects of forest management on forest hydrology. By linking forest growth and hydrology, it should be possible to determine spatially differentiated the extent to which development and management of forest stands results in changes of water regime. The main components of the system are the forest growth simulator WaldPlaner (release $1.4 \mathrm{~g}$, Hansen, 2006) and the spatially-differentiated hydrological model WaSiM-ETH (release 8.2.9, Schulla and Jasper, 2007). Based on forest inventory data, WaldPlaner simulates the development of forest stands for different forest management scenarios. The essential hydrological processes are simulated physically with the raster-based model WaSiM-ETH.

The parametrization of the models and interactive forest growth-hydrologic modelling was conducted exclusively for forested areas. Given the different forest development scenarios, the effects of forest management practices on the regional hydrology in forests were investigated. The simulation periods extended from 2006 to 2055 . To exclude the

Published by Copernicus Publications on behalf of the European Geosciences Union. 


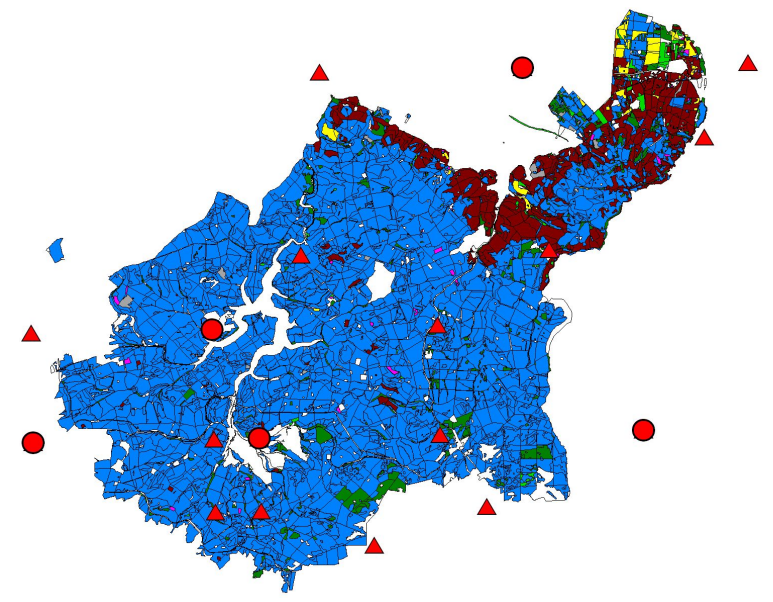

Legend

- climate station

$\Delta$ precipitation station

stand type

$\square$ oak

beech

noble hardwood

other hardwood

spruce

douglas fir

pine

larch

Fig. 1. Overview of the Oker catchment (Northern Harz Mountains) with stand type and climate stations (white areas: non-forest land use).

effects of climatic change on forest growth, the hydrological model was driven with observed meteorological data collected between 1956 and 2005 .

\section{Study area}

The Oker catchment is located in the northern Harz Mountains of Lower Saxony (Germany) at an elevation between 200 and $1000 \mathrm{~m}$ a.s.l. The climate is temperate and humid. Mean annual temperature decreases from $8.5^{\circ} \mathrm{C}$ at lower elevations to $6.0^{\circ} \mathrm{C}$ at the highest peaks. Annual precipitation ranges from $780 \mathrm{~mm}$ at the foothills of the Harz Mountains to more than $1200 \mathrm{~mm}$ at the highest elevations. Data for precipitation, wind speed, temperature, global radiation, and relative humidity were obtained from climate stations and precipitation stations of the German Weather Service (Fig. 1).

The study area is about 15000 ha in size. More than $80 \%$ of the actual forest stands are dominated by Norway spruce, about $10 \%$ by beech and less than $10 \%$ by oak, larch and other hardwood species (Fig. 1). Broadleaved species primarily occur in the lowlands. With increasing elevation the competitive capability of beech relative to spruce decreases. At between 650 and $850 \mathrm{~m}$ a.s.l. natural submontane beech forests change to montane spruce forests.

The parametrization of the hydraulic properties of the unsaturated zone is based on a detailed forest site map. For each soil horizon thickness, soil texture and stone content are available. Soils are predominantly of loamy-sandy and silty-loamy texture (more than $75 \%$ of the study area) with mostly vertical water flux.

\section{Models and methods}

In addition to the observation of actual hydrological processes, the assessment of long-term changes to the water regime arising from forestry practices is important for the development of management strategies. Thus, simulations of stand development were carried out using a forest growth model for different assumed forest management activities. The results of the forest development scenarios were entered into the hydrological model to estimate water fluxes in the study catchment under different conditions of forest structure. Through this approach hydrological changes are quantified and spatially differentiated.

\subsection{The forest growth simulator WaldPlaner}

The modelling system WaldPlaner (Hansen, 2006) was used to simulate the growth and management of forest stands. The growth functions of the stand simulator are based on extensive datasets from forest yield studies. The model is based on the single tree generator TreeGrOSS (Nagel and Schmidt, 2006) and supports the generation of virtual model stands from forest inventory data, single-tree inventories or complete surveys (Fig. 2). The virtual stands are established tree by tree based on actual stand characteristics, and stand growth is simulated according to various forest management strategies.

The integrated scenario manager permits a wide range of silvicultural strategies to be used in the simulation, which also include options for stand tending, wood harvesting and forest regeneration. These individual measures are then incorporated into forest development scenarios (Fig. 2). Forest stand development is also influenced by decisions on the final cutting system and the forest renewal phase (tree species selection, planting, natural regeneration, thinning). In the forest growth simulator, tree species composition is controlled by the forest development type selected. WaldPlaner provides the user with predefined forest development scenarios. These comprise standard rules, which, for example, allow tree species composition and proportional mixture of tree species to be varied. Yet WaldPlaner also permits the user to define site-specific forest development strategies if desired (Fig. 2) 

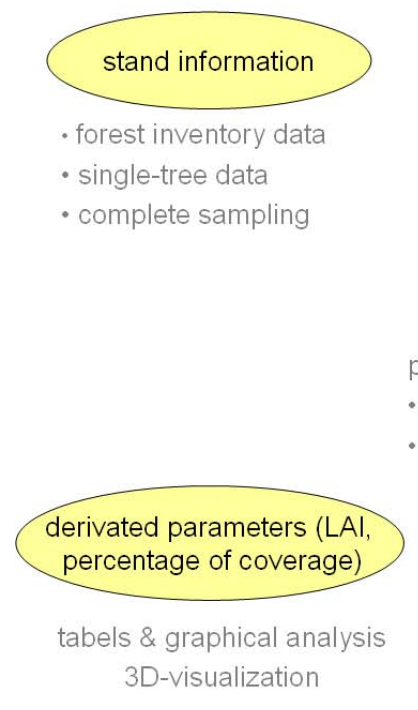
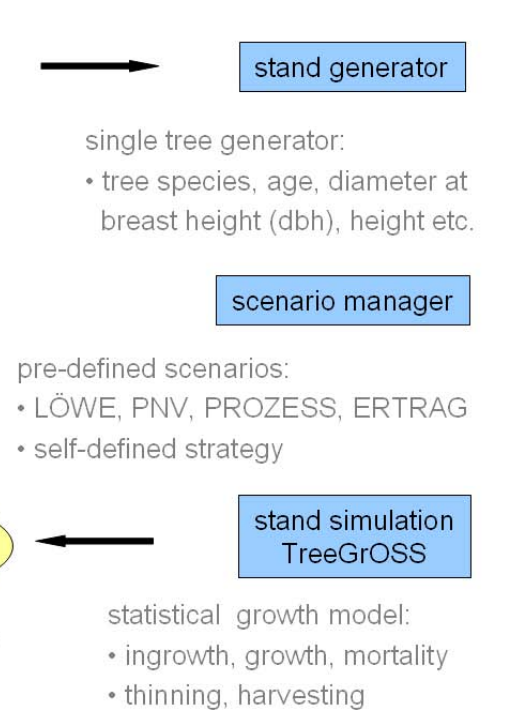

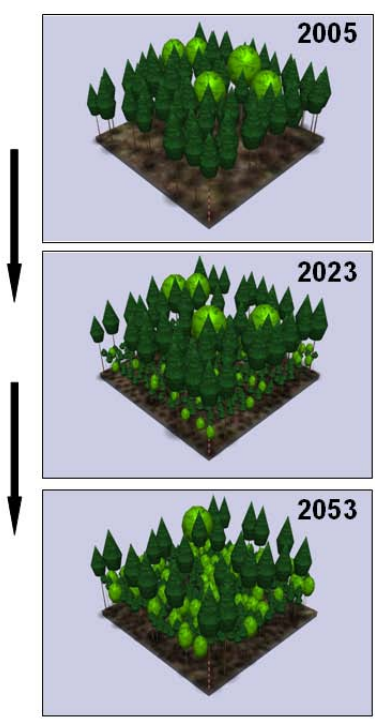

Fig. 2. Stand simulation of a European beech Norway spruce mixed stand with WaldPlaner.

Stand simulation can be conducted for as many sites as required. At the beginning of forest growth simulation, the prediction period (e.g. 50 years), output interval (e.g. 5 years), forest development scenario, type of forest development, mortality rate in addition to a range of other possible planning measures must be specified. Then, forest growth is calculated for each simulation interval on a single-tree basis and the results stored in a simulation database. Output parameters, including tree species, stem number, canopy cover and diameter, height and volume development are produced for further processing in other modules of the modelling system. The resulting output is provided in tabular form, or as diagrams or 3-D images (Fig. 2).

\subsection{The hydrological model WaSiM-ETH}

The hydrological model WaSiM-ETH (Schulla and Jasper, 2007) calculates the water fluxes on a regular grid and simulates the discharge in catchments using a routing scheme. To model water fluxes, spatially distributed orographic, land use and soil data are needed. The GIS database consists of the digital elevation model, forest inventory data and forest site maps. The forest inventory sites and forestry site maps were transferred to a $100 \times 100 \mathrm{~m}$ grid and recorded by dominant topographic features. Small areas, those with an area much smaller than one hectare, were not considered by the hydrological model in this approach.

Time series for precipitation, wind speed, temperature, global radiation, and relative humidity were entered into the hydrological model as daily mean or daily sum values. Station based meteorological data are interpolated using different methods (inverse distance weighting, elevationdependent regression, or combination of both) onto the model grid. The model includes a wind-dependent correction for weather station recordings of precipitation. In addition, a radiation correction and temperature modification were performed to account for site topographic differences.

Evapotranspiration describes the processes of transpiration, interception and evaporation. Interception is determined by WaSiM-ETH using a simple storage approach. Potential evapotranspiration is estimated according to the Penman-Monteith approach (Monteith, 1965). PenmanMonteith aerodynamic resistance is calculated from wind velocity and roughness length, where roughness length is a function of stand height. The canopy resistance is seasonally adjusted.

WaSiM-ETH simulates water fluxes in the unsaturated soil zone based on the Richards equation (Richards, 1931) in one dimensional vertical form. The soil water retention function used is parameterized according to van Genuchten (1980). The physical characteristics of forest soils differ substantially from arable soils. For this reason, in this study the van Genuchten parameters were derived according to Teepe et al. (2003). Characteristic soil profiles were obtained from forest site maps.

The model was calibrated using observed discharge from three subcatchments of the Oker catchment (i.e. Lange Bramke, Kalbe, Radau). The period of 1990 to 1999 was used for calibration, whereas the period of 1950 to 1989 served for validation purposes. For the evaluation of model performance, we used the Nash-Sutcliffe model efficiency coefficient (Nash and Sutcliffe, 1970). Furthermore, stand precipitation (i.e. precipitation beneath the canopy) from intensive monitoring plots at Lange Bramke was used for the calibration of the interception module (Meesenburg et al., 2010). 


\subsection{Derivation of stand-specific parameters for hydrological models}

Independent models for the simulation of forest growth and hydrology were coupled through a common database. All model parameters and simulation results were managed in the database, and accessed by both models. The results of the stand simulation were either entered directly into the hydrological model (e.g. leaf area index) via a central database interface, or used to derive stand parameters (e.g. rooting depth as a function of stand age).

At the beginning of a simulation cycle, model stands were generated in WaldPlaner. For each single tree, tree characteristics such as age, diameter at breast height were calculated and entered into the database. A comprehensive system of rules, implemented in the database, was followed to determine all stand-specific parameters from single-tree data and process them for the hydrological model.

The degree of canopy cover was calculated directly for each stand in WaldPlaner, and could have values between 0 and 1.0 (complete canopy cover). If less than $85 \%$ of the stand area was under canopy cover, a secondary vegetation layer (ground vegetation) was considered. Highly structured stands with several tree layers can also be reproduced in the hydrological model.

The leaf area index (LAI) is calculated according to Eq. (1). According to the mean diameter at breast height (dbh) and stand density $\left(N_{\mathrm{S}}\right)$ of the stand, the maximum LAI was derived for each tree species (Hammel and Kennel, 2001). The leaf or needle fall reflected in LAI reveals the seasonal changes. The LAI for a Norway spruce stand in the dormant period is $80 \%$ of maximum LAI. For broadleaved species, the LAI in winter corresponds to the stem area index (SAI).

$\mathrm{LAI}=f_{\mathrm{p}} \cdot N_{S} \cdot A_{l}(\mathrm{dbh})$

$\mathrm{dbh}=$ diameter at breast height,

$f_{\mathrm{p}}=$ tree species-specific factor,

$N_{\mathrm{S}}=$ stand density,

$A_{l}(\mathrm{dbh})=a_{1}(\mathrm{dbh})+a_{2}(\mathrm{dbh})^{2}+a_{3}(\mathrm{dbh})^{3}$

with $a_{1}, a_{2}, a_{3}$ regression parameters describing the relation between foliar surface and dbh.

The Fig. 3 schematically shows the calculation of the LAI for Norway spruce. In the underlying forest development scenario, thinning operations were carried out every five years. In keeping with these operations, the stand density decreased such that a decrease in LAI every five years was also evident. In subsequent years LAI increased again slightly with tree growth.

The maximum rooting depth was derived in relation to stand age and soil substrate following Raissi et al. (2009). Rooting depth was assumed independent of tree species.

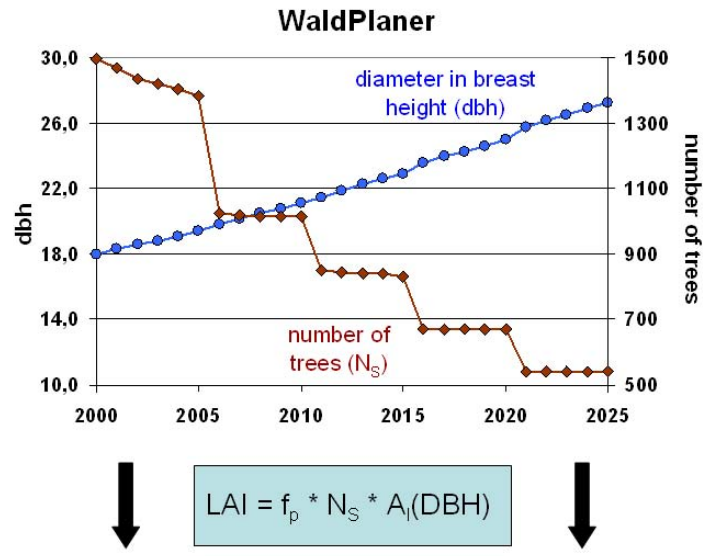

WaSiM/ETH

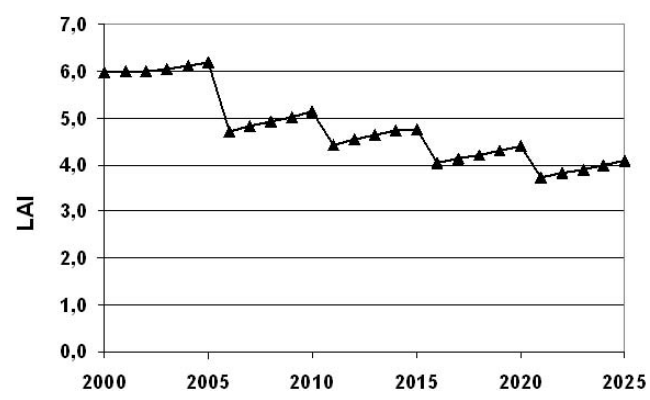

Fig. 3. Calculation of leaf area index for a Norway spruce stand from the LOEWE scenario.

\section{Results}

\subsection{Forest development scenarios}

The silvicultural options investigated should exemplify the range of variation in possible forest management strategies. The scenario near-natural silviculture "LOEWE", representing long-term ecological forest development, adopted a balance between economical utilisation and ecology, in that the utilisation, protection and recreation functions of forests were accorded equal priority.

Today many forests no longer portray the natural vegetation due to prolonged anthropogenic influences. In the simulation scenario "potential natural vegetation" (PNV), the tree species composition was altered such that stands were converted to a near-natural condition over time. For forested areas in the Oker catchment, this means that current stands, predominantly pure Norway spruce stands, were converted to stands dominated by European beech in the long-term.

The scenario "ERTRAG" focussed more on economic goals. Here the preferred tree species were those that promise the highest economic benefit for the given site factors. While forestry operations occurred less frequently, they were also more intensive. Forests managed primarily for yield are often pure stands, which have a more simplistic structure with fewer vegetation layers. 
For the forest development scenario "PROZESS", no harvesting operations were carried out during the entire simulation period. Rather, the most competitive tree species in the stand became the dominant species. The reduction of stand density only resulted from natural mortality.

A basis scenario "status quo" (Forest inventory, 2003), in which the stand data were unchanged up to the year 2055, was simulated with the hydrological model to facilitate an assessment of the effects of silvicultural measures on forest hydrology.

\subsection{Hydrology}

The effect of silvicutural practices on forest hydrology can be assessed from a comparison of the annual sums of evapotranspiration and runoff. At the beginning of the simulation period, in year 2006, all forest development scenarios began with the same parameter set. This explains the relatively small differences in the amount of evapotranspiration calculated early in the simulation period (Fig. 4). However, already after 10 to 15 years, distinct differences in the actual evapotranspiration amount calculated occurred particularly between the ERTRAG and PROZESS scenarios. Due to the high biomass growth rates in PROZESS, the evapotranspiration in forest stands clearly increased whereas, for the yield-based scenario ERTRAG, a decrease in the actual evapotranspiration was evident at the centre of the area as a result of the intensive forestry operations performed. The stronger opening up of many of these stands compared to other scenarios caused interception in particular to fall markedly. The evapotranspiration calculated for the scenario ERTRAG was initially similar to that of the status quo. In the first years, the forest development scenarios LOEWE and PNV showed only a slight rise in evapotranspiration (Fig. 4).

By the end of the simulation period, the differences in evapotranspiration amounts calculated increased between forest development scenarios. Whereas for the scenario PROZESS the mean actual evapotranspiration of $650 \mathrm{~mm}$ at the beginning of the simulation period increased to almost $740 \mathrm{~mm}$, the mean actual evapotranspiration for ERTRAG dropped to about $620 \mathrm{~mm}$. According to the changes in evapotranspiration, a reduction (PROZESS) and increase (ERTRAG) in runoff compared to the status quo were simulated (Table 1). Minor differences in evapotranspiration calculations were found for the scenarios LOEWE and PNV compared to the control scenario up to year 2025. Thereafter, evapotranspiration in PNV rose slightly above the status quo, falling back to the status quo level by the end of the simulation period. In LOEWE many stands reach harvestable size by the end of the simulation period so that the mean actual evapotranspiration of these stands after harvesting decreased to $637 \mathrm{~mm}$, thus approaching the level of the ERTRAG scenario.

The runoff coefficient gives the quotient of runoff over precipitation. The higher the coefficient is, the greater the runoff in the water budget relative to precipitation. In the study

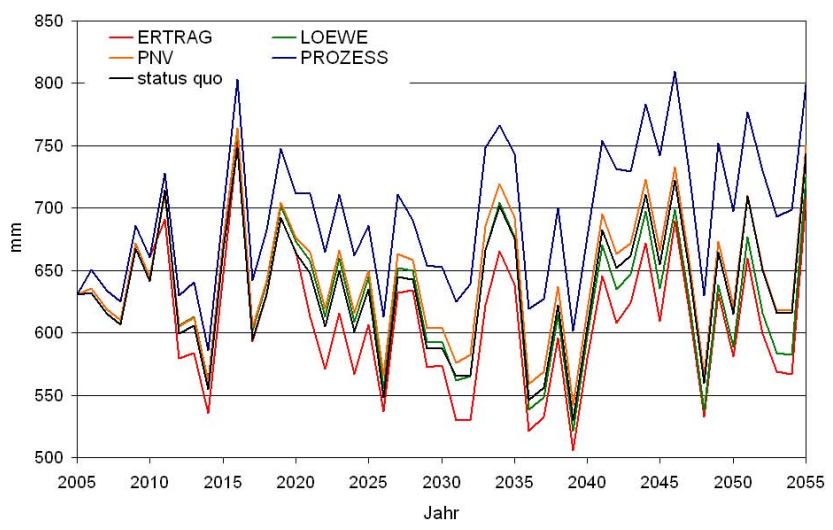

Fig. 4. Simulated actual evapotranspiration for different forest development scenarios.

Table 1. Water budget components calculated (in $\mathrm{mm} / \mathrm{a}$ ) for different forest development scenarios, mean values for the years 2051-2055.

\begin{tabular}{lccccc}
\hline & $\begin{array}{c}\text { status } \\
\text { quo }\end{array}$ & LOEWE & PNV & ERTRAG & PROZESS \\
\hline $\begin{array}{l}\text { precipitation } \\
\text { evapotran- } \\
\text { spiration }\end{array}$ & 667 & 1283 & 1283 & 1283 & 1283 \\
$\begin{array}{l}\text { runoff } \\
\text { runoff }\end{array}$ & 640 & 658 & 629 & 672 & 566 \\
coefficient & 0.50 & 0.51 & 0.49 & 0.52 & 0.44 \\
\hline
\end{tabular}

area high runoff coefficients were obtained on those areas with above-average total precipitation (Fig. 5). As precipitation distribution was clearly dependent on elevation in the Oker catchment, the highest runoff coefficients of over 0.7 occurred near Mt. Brocken, the highest point on the mountain range. The lowest proportion of runoff of less than 0.1 was found in forested areas at the foothills of the mountain range where, on average, over $90 \%$ of the precipitation was lost by evapotranspiration. Higher runoff coefficients were simulated for lower total precipitation only on areas without forests or in very open stands.

Towards the end of the simulation period, the differences in the water balances calculated were higher compared to the status quo for almost all forest development scenarios (Table 1). High stand densities and above-average stand age of forests caused the mean runoff coefficient for PROZESS to drop to 0.44 compared to 0.5 in the status quo scenario. Evapotranspiration is correspondingly high in this scenario (Fig. 4, Table 1). The moderate use of forest areas in the LOEWE scenario meant that the mean runoff coefficient increased only very slightly. The PNV scenario revealed the smallest changes throughout the simulation period. 


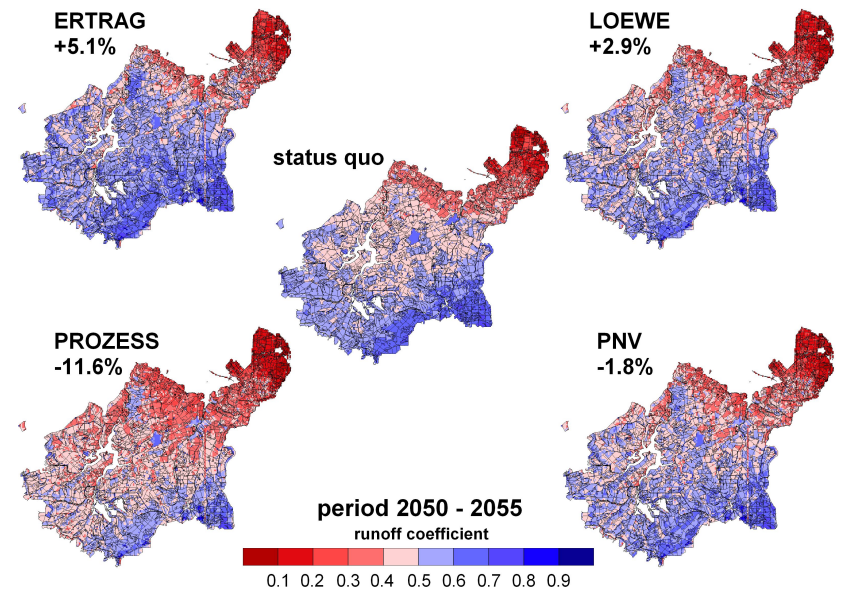

Fig. 5. Runoff coefficient for different forest development scenarios.

\section{Summary/conclusions}

The results of the simulations show that forest management may have a distinct effect on water budgets of forests. This has already been shown for Lange Bramke, a subcatchment of the study area (Meesenburg et al., 2010) and several other forested catchments (Bosch and Hewlett, 1982; Gallart and Llorens, 2003). In the Oker catchment, two of the studied forest management strategies (LOEWE and PNV) had only small effects on water budget components as related to the status quo. For the scenarios ERTRAG and PROZESS considerable changes in water budgets are estimated with either decreased (ERTRAG) or increased (PROZESS) evapotranspiration rates. Generally, silvicultural strategies resulting in high standing biomass with large foliage quantities can be regarded as water demanding. Thus, if drought stress is a frequently occurring phenomenon or maximum water yield from the catchment is aspired, forests should be managed in a way that the water demand of the trees is a low as feasible. This can be achieved by intensified thinnings or conversion to less water demanding tree species.

The findings from the scenario analyses should be regarded with care, since simulation results are equipped with large uncertainty due to uncertainty in input data and possibly weak model formulations. However, the dynamic treatment of forest stand structure in the hydrological model improves the analysis of effects of silvicultural measures on water budgets substantially. A next step for the improvement of the forest growth-hydrology coupling would be the inclusion of a site index model into the growth simulator, which simulates tree growth dependent on climatic and site specific variables (Albert and Schmidt, 2010).

Acknowledgements. The funding of the study by the Lower Saxonian Ministry for Environment and Climate Protection and the Lower Saxonian Ministry for Food, Agriculture, Consumer Protection, and Rural Development is gratefully acknowledged.
Edited by: A. Wahren, F. Tavares Wahren, and K.-H. Feger

Reviewed by: two anonymous referees

\section{References}

Albert, M. and Schmidt, M.: Climate-sensitive modelling of siteproductivity relationships for Norway spruce (Picea abies (L.) Karst.) and common beech (Fagus sylvatica L.), Forest Ecol. Manag., 259(4), 739-749, 2010.

Bosch, J. M. and Hewlett, J. D.: A review of catchment experiments to determine the effect of vegetation changes on water yield and evapotranspiration, J. Hydrol., 55, 3-23, 1982.

European Parliament and of the Council: Directive 2000/60/EC of the European Parliament and of the Council establishing a framework for the Community action in the field of water policy, 2000.

Gallart, F. and Llorens, P.: Catchment Management under Environmental Change: Impact of Land Cover Change on Water Resources, Water Int., 28, 334-340, 2003.

Hammel, K. and M. Kennel: Charakterisierung und Analyse der Wasserverfügbarkeit und des Wasserhaushalts von Waldstandorten in Bayern mit dem Simulationsmodell BROOK90, Forstliche Forschungsberichte München, 185, 2001 (in German).

Hansen, J.: Der WaldPlaner - Ein System zur Entscheidungsunterstützung in einer nachhaltigen Forstwirtschaft, Deutscher Verband Forstlicher Forschungsanstalten - Sektion Forstliche Biometrie und Informatik, Trippstadt, 112-119, 2006 (in German).

Meesenburg, H., Sutmöller, J., and Hentschel, S.: Retrospective and prospective evaluation of water budgets at Lange Bramke, Harz Moutains, Germany: effects of plant cover and climate change, in: Status and Perspectives of Hydrology in Small Basins, Proceedings of the Workshop held at Goslar-Hahnenklee, Germany, 30 March-2 April 2009, IAHS Publ. 336, 239-244, 2010.

Monteith, J. L.: Evaporation and environment, Symp. Soc. Exp. Biol., 19, 205-224, 1965.

Nagel, J. and Schmidt, M.: The Silvicultural Decision Support System BWINPro, in: Sustainable Forest Management, Growth Models For Europe, edited by: Hasenauer, H., Springer, Berlin, Heidelberg, 59-63, 2006.

Nash, J. E. and Sutcliffe, J. V.: River flow forecasting through conceptual models, Part I - A discussion of principles, J. Hydrol., 10, 282-290, 1970.

Raissi, F., Müller, U., and Meesenburg, H.: Ermittlung der effektiven Durchwurzlungstiefe von Forststandorten, 3rd edn., GeoFakten 9, 7 pp., available at: http://www.lbeg.niedersachsen.de/ live/live.php?navigation_id=616\&article_id=872\&_psmand $=4$, 2009 (in German).

Richards, L. A.: Capillary conduction of liquids through porous mediums, Physics, 1(5), 318-333, 1931.

Schulla, J. and Jasper, K: Model description WaSiM-ETH, Technical Report, 181 pp., available at: http://www.wasim.ch/ downloads/doku/wasim/wasim_2007_en.pdf, 2007.

Teepe, R., Dilling, H., and Beese, F: Estimating water retention curves of forest soils from soil texture and bulk density, J. Plant Nutr. Soil Sc., 166, 111-119, 2003.

van Genuchten, M. T.: A closed-form equation for predicting the hydraulic conductivity of unsaturated soils, Soil Sci. Soc. Amer. J., 44(5), 892-898, 1980. 